\title{
Computer Implementation for Analysis of Complex Masonry Shell Structures
}

\author{
Jerzy Szolomicki, Piotr Berkowski \\ Faculty of Civil Engineering \\ Wroclaw University of Technology \\ Wroclaw, Poland \\ e-mail: Jerzy.Szolomicki@pwr.wroc.pl
}

\begin{abstract}
Strong interest in masonry complex historical structures and the need to understand their static and dynamic behavior has led to the development of computational methods used to analyze the masonry vaults. This paper concerns the numerical modeling of the static behavior of masonry vaults. In the introduction, a description of the geometry of presented vaults and then FEM applied to numerical analysis are presented. The authors describe a generally accepted basic principles of finite element method for static and dynamic analysis of such structures. Next, this method is used to static analysis of different types of vaults: barrel, sex-partite and cloister ones. Such structures were barely discussed in detail because of the difficulties in applying the classical theory of line pressure for such a complex geometry.
\end{abstract}

Keywords-computer analysis; finite element method; masonry shell structures

\section{INTRODUCTION}

Construction of vaults, domes, and other multi-curvature structures are a very common type of structures of historical buildings. The vaults were shaped so that their cross sections were only under compressive stresses, which correspond to their geometry, the conduct of the pressure line dependent on the way of loading and boundary conditions.

Great interest in the protection and rehabilitation of these structures has created a need to develop new effective tools to analyze and assess the resistance of such structures. Application of FEM to the analysis of complex masonry shell structures is presented in the papers $[1,2,5]$. In current paper the different types of masonry vaults were examined, Figure 1. Surface finite elements were used to define structural geometric models. Although the form of the vaults are not so different, areas that create them have different characteristics. The behavior of each area may be different due to their cylindrical or elliptical-parabolic shape. Surfaces can be singly or doubly curved.

In the singly curved vaults principal stresses situated along the curve are always compressive, and the pressure line system requires adequate weight of supporting system due to the relatively large forces of expansion.

An example of singly-curved ceiling is barrel vault with the shape of laying half of cylinder cut along a horizontal plane. This vault can be semi-circular, parabolic, elliptical or arched.

Doubly curved vaults can be shaped as elliptic-parabolic ones. This type of vault is used mainly to cover square or rectangular areas. In these vaults of the principal stresses are compressive in the direction of the both curves. Cracks occur as a result of displacement of the supports. This type of vaults includes cross vaults, cloister, and sexpartite ones.

Cross vault is made up of two intersecting barrel vaults, form only the upper parts are left. It is supported on four columns located at the square corners. Supports are under the diagonals emerging by the intersection of the cradles, along which the load is transferred.

Cloister vault also arises from the intersection of the two barrel vaults established in a square plane, but in a different way. Rather than rest on four pillars it requires reliance on the four walls. As heavier and less practical its use was less common.

Sex-partite vault is divided in plane by two diagonals and one transverse rib, in which six webs meet at a central point.

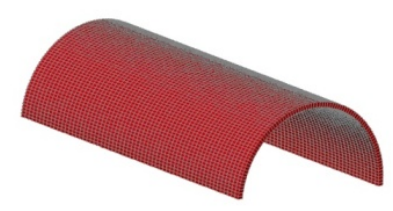

a)

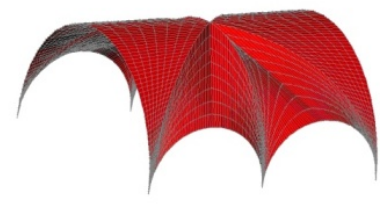

c)

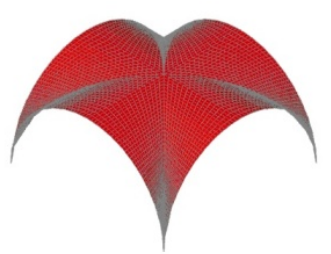

b)

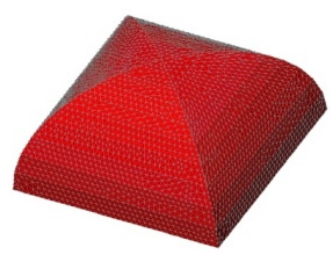

d)
Figure 1. Different types of analyzed vaults: a) barrel vault,b) cross vault, c) sex-partite vault, d) cloister vault.

\section{COMPUTATIONAL METHOD}

The main problem of the analysis of complex masonry structures is formulation of a proper mathematical model, through which we can get results consistent with experimental studies carried out on the real object. The mathematical formulation assumes small displacements of the structure, $[7,8]$. The components of the deformation can be written as:

$$
\varepsilon_{1}=\varepsilon_{1}^{0}+\mathrm{z} \bar{\chi}_{1}, \varepsilon_{2}=\varepsilon_{2}^{0}+\mathrm{z} \bar{\chi}_{2}, \gamma_{12}=\gamma_{12}^{0}+\mathrm{z} \bar{\tau}
$$




$$
\gamma_{1 \mathrm{z}}=\frac{R_{1}}{R_{1}+\mathrm{z}} \gamma_{1 \mathrm{z}}^{0}, \quad \gamma_{2 \mathrm{z}}=\frac{R_{2}}{R_{2}+\mathrm{z}} \gamma_{2 \mathrm{z}}^{0}
$$

where:

$\varepsilon_{1}, \varepsilon_{2}, \gamma_{12}$ - the normal and shearing strains, $\varepsilon_{1}{ }^{0}, \varepsilon_{2}{ }^{0}, \gamma_{12}{ }^{0}$ - the normal and shearing strains of the middle surface, $\gamma_{1 z}, \gamma_{2 z}$ the thickness shearing strains, $\gamma_{1 z}{ }^{0}, \gamma_{2 z}{ }^{0}-$ the thickness shearing strains of the middle surface, $\chi_{1}, \chi_{2}, \tau$ - the changes of curvature of the middle surface, $R_{1}, R_{2}$ - the principal radii of curvature of the middle surface of the shell.

Formulation of the strain energy for moderately thick shells, containing the effects of thickness shear deformations and the terms involving $(1+\mathrm{z} / R)$,

$V=\frac{E h}{2\left(1-v^{2}\right)} \int_{A} Q_{0} d A+\frac{E h^{3}}{24\left(1-v^{2}\right)} \int_{A} Q_{2} d A+\frac{E h}{2\left(1-v^{2}\right)} \int_{A} Q_{3} d A$

where:

$Q_{0}, Q_{2}, Q_{3}$ represent the strain energy of membrane, bending-additional, and shear terms, respectively, $\mathrm{h}$ is the thickness of shells, E, v - Young's modulus, Poisson's ratio.

The element stiffness matrix and the load vector are determined by using the theorem of minimum potential energy. The element stiffness matrix can be written by the sum of the stiffness contributed from the membrane, bending, shear effect, as well an additional effect. That is:

$$
[k]^{\mathrm{e}}=[k]_{\mathrm{b}}^{\mathrm{e}}+[k]_{\mathrm{s}}^{\mathrm{e}}+[k]_{2}^{\mathrm{e}}
$$

The following expressions for the element stiffness matrices can be received, respectively:

$$
\begin{gathered}
{[k]_{\mathrm{b}}^{\mathrm{e}}=\int_{A}[B]_{\mathrm{b}}^{\mathrm{T}}[D]_{\mathrm{b}}[B]_{\mathrm{b}} \mathrm{d} A,} \\
{[k]_{\mathrm{s}}^{\mathrm{e}}=\int_{A}[B]_{\mathrm{s}}^{\mathrm{T}}[D]_{\mathrm{s}}[B]_{\mathrm{s}} \mathrm{d} A,} \\
{[k]_{2}^{\mathrm{e}}=\int_{A}[B]_{2}^{\mathrm{T}}[D]_{2}[B]_{2} \mathrm{~d} A .}
\end{gathered}
$$

In these expression $[k]_{\mathrm{b}}^{\mathrm{e}},[k]_{\mathrm{s}}^{\mathrm{e}}$ and $[k]_{2}^{\mathrm{e}}$ are the element of bending, shear and additional stiffness matrices, respectively.

For the earthquake response of the construction, a finite element formulation for linear dynamic analysis of shells of any shape is shown. The displacement $U, V$ and $W$ at a point $\mathrm{z}$ away from the shell middle surface are formulated as:

$$
\begin{gathered}
U\left(\alpha_{1}, \alpha_{2}, \mathrm{z}, t\right)=u\left(\alpha_{1}, \alpha_{2}, t\right)+\mathrm{z} \alpha\left(\alpha_{1}, \alpha_{2}, t\right), \\
V\left(\alpha_{1}, \alpha_{2}, \mathrm{z}, t\right)=v\left(\alpha_{1}, \alpha_{2}, t\right)+\mathrm{z} \beta\left(\alpha_{1}, \alpha_{2}, t\right),
\end{gathered}
$$

$$
W\left(\alpha_{1}, \alpha_{2}, \mathrm{z}, t\right)=w\left(\alpha_{1}, \alpha_{2}, t\right)
$$

where:

$t$ is the time, $u, v, w$ are the in-plane and transverse displacements on the middle surface, $\alpha, \beta$ are the rotations of tangents to the middle surface along the parametric lines $\alpha_{1}$ and $\alpha_{2}$ respectively.

The equation of motion is originated from Hamilton's variational principle, which can be written as:

$$
\int_{t_{1}}^{t_{2}} \delta(\pi-T) \mathrm{d} t=\int_{t_{1}}^{t_{2}} \delta W_{n} \mathrm{~d} t=0
$$

where:

$\pi$ - the total potential energy containing both the strain energy and the potential of any conservative external forces, $T$ - the total kinetic energy, $W_{n}$ - the work done by nonconservative forces.

Analyzing the strains and inserting in the expression:

$$
\pi=\frac{1}{2} \int_{V}\{\varepsilon\}^{T}\{\sigma\} \mathrm{d} V-\int_{A}\{f\}^{T}\left\{P_{c}\right\} \mathrm{d} A
$$

where:

$\left\{P_{c}\right\}$ is the vector of force in the direction $\left(\alpha_{1}, \alpha_{2}, z\right),\{f\}$ is the displacement of any generic point in the shell space.

The kinetic energy $\mathrm{T}$ can be presented as:

$$
T=\frac{1}{2} \int_{V}\{\dot{f}\}^{T} \rho\{\dot{f}\} d V
$$

where:

$\rho$ is the mass density of the material, $\{\dot{f}\}=\{\dot{U} \dot{V} \dot{W}\}$ - the velocity vector of any generic point.

The final expression of kinetic energy in the matrix form can be presented as:

$$
T=\frac{1}{2} \int_{A}\{\dot{q}\}^{T}[P]\{\dot{q}\} \mathrm{d} A
$$

where: $\{\dot{q}\}=\left\{\begin{array}{llll}\dot{u} \dot{v} & \dot{w} & \dot{\alpha} & \dot{\beta}\end{array}\right\}^{T}$.

The energy dissipation $W_{n}$ can be expressed:

$$
W_{n}=\int_{A}\{f\}^{T}\left\{P_{n}\right\} \mathrm{d} V
$$

where:

$\left\{P_{n}\right\}$ is the non-conservative force vector per unit volume. 
For the case of viscous damping $W_{n}$ can be written as:

$$
\left.\left.W_{n}=\int_{A}\{q\}^{T}[c]\right\} \dot{q}\right\} \mathrm{d} A .
$$

By substituting the expressions for $\pi, T$ and $W_{n}$ in Equation (11) and matrix displacements relations, the following equation of motion is received as follows:

$$
\int_{t_{1}}^{t_{2}} \delta\left\{q_{i}\right\}^{e T}\left[[M]^{e}\left\{\ddot{q}_{i}\right\}^{e}+[C]^{e}\left\{\dot{q}_{i}\right\}^{e}+[K]^{e}\left\{q_{i}\right\}^{e}-\{F\}^{e}\right] \mathrm{d} t=0,
$$

where:

$[M]^{e}$ - element consistent mass matrix, $[C]^{e}$ - element damping matrix, $[K]^{e}$ - element stiffness matrix, $\{F\}^{e}-$ element load vector, $\left\{q_{i}\right\}$ - nodal displacement vector.

Depending on the purpose of the investigation, two main solution are possible in most of the FE software, static and dynamic analysis. In static analysis no inertia or dissipative resistance is activated, while dynamic analysis examines how the external loads are balanced with inertial, dissipative and elastic resistance of the system.

\section{NUMERICAL EXAMPLES}

Numerical FEM analyses are performed using LUSAS code (release 14.7). Vaults are modeled using shell elements. Four vault typologies are analyzed (barrel, cross, sex-partite and cloister vaults) while parametrically varying geometrical proportions and constraints, Figs 2-5.

The FEM simulations are performed with dead loads and the presence of fill and backfill is neglected. The proposed analyses lead in any case to stiffness estimation at the safe side. For each of the calculations, the homogenized approach has been employed, assuming for the constituent materials experimentally determined mechanical properties [6].

The first analysis relies on the determination of distribution of principal stress $\sigma_{1}$ of a barrel rectangular vault [4]. The vault is a circular arch with a span of $4 \mathrm{~m}$, a width of $8 \mathrm{~m}$ and a thickness of $0,12 \mathrm{~m}$, Fig. 2 .

A cross vault formed by the intersection of two barrel vaults with an external radius of $4 \mathrm{~m}$, is considered as the next example [4], Fig. 3.

The third analysed example was a sexpartite vault divided into six bays by two diagonal ribs and three transverse ribs, with an external radius of $4 \mathrm{~m}$, Fig. 4.

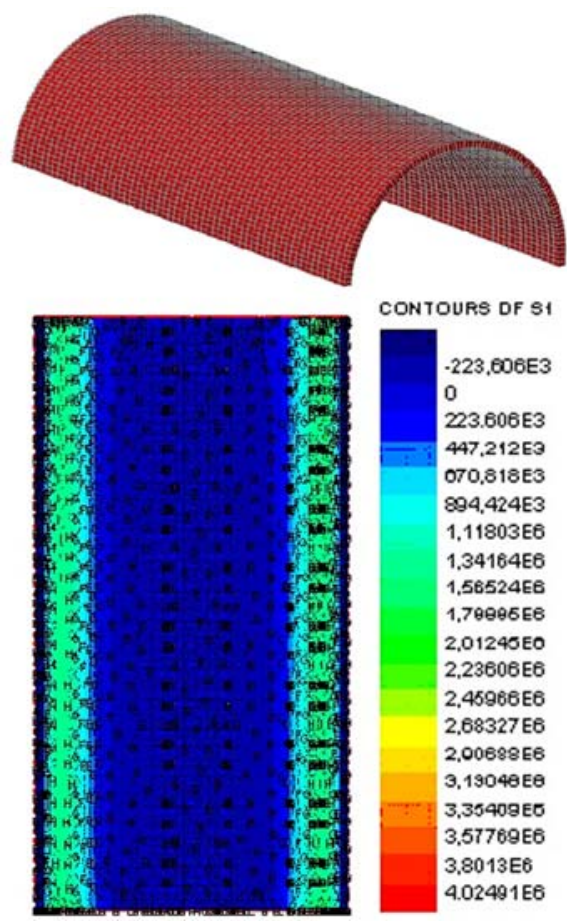

Figure 2. A diagram of principal stresses $\sigma_{1}$ for the barrel vault subjected to dead-weight loading.
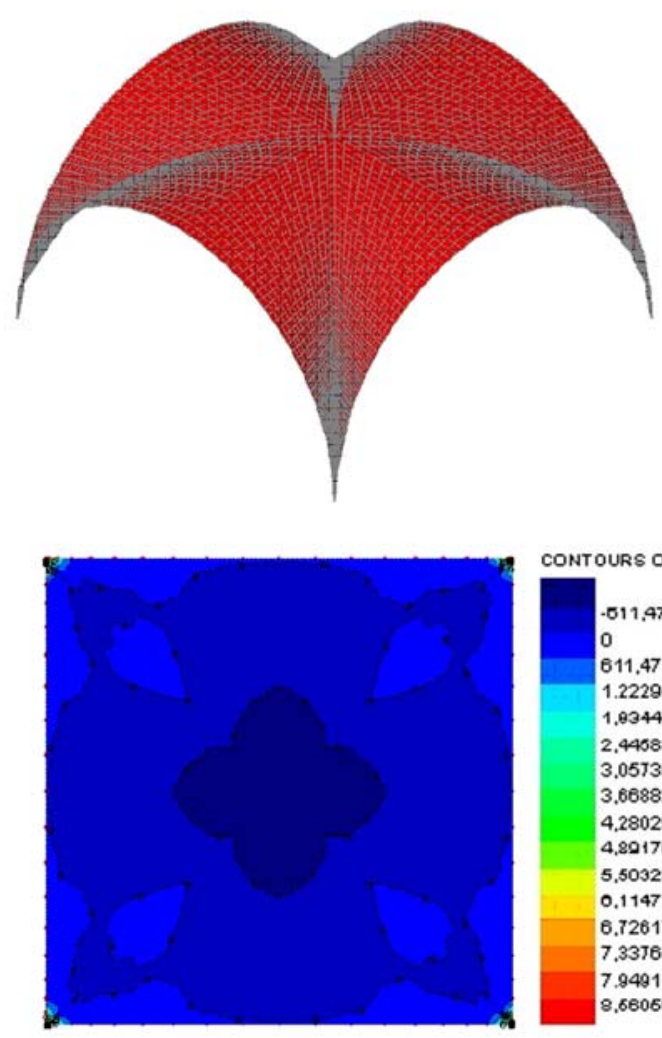

CONTOURS OF $\$ 1$

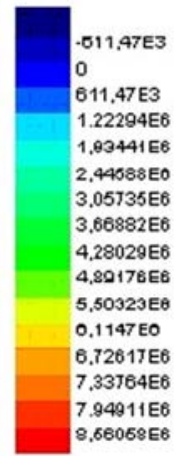

Figure 3. A diagram of principal stresses $\sigma_{1}$ for the cross vault subjected to dead-weight loading. 


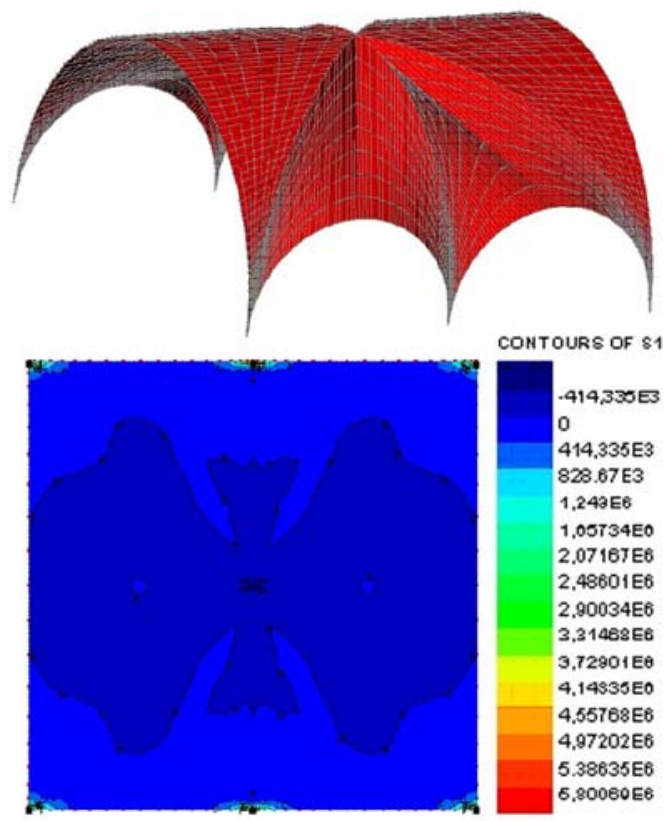

Figure 4. A diagram of principal stresses $\sigma_{1}$ for the sexpartite vault subjected to dead-weight loading.
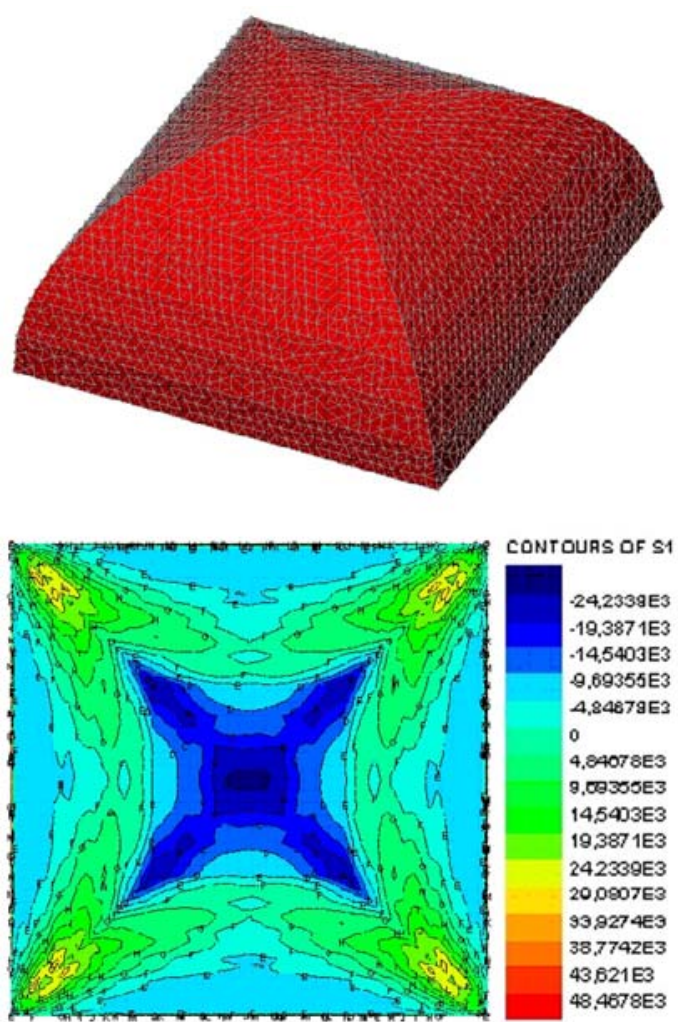

Figure 5. A diagram of principal stresses $\sigma_{1}$ for the sexpartite vault subjected to dead-weight loading.
The last example was a cloister vault with a square $(4 \mathrm{~m})$ base from which curved segments rise to a central point, Fig. 5.

\section{CONCLUSIONS}

The methods presented in this paper are very useful in studying the static and dynamic behavior of large range of masonry vaults subjected to very general load conditions, both for damage analyses and solving equilibrium problems. The study proves the reliability of the model and good compatibility of the results deriving from the implementation of the proposed theoretical method [8,9] with the data relevant to the laboratory experimentation. The development of a computer method is of great importance with regard to strengthening interventions because it allows understanding the cause of the cracks initiation and its propagation. Furthermore, the vaults are often analyzed as arches situated side by side, but which do not work together. The results obtained by the FEM show that this arch approach, especially for complex vault (cloister, sex-partite vaults), do not provide correct values about current stress field. In the case of these vaults, it is emerged the importance of the interaction between arches for the evaluation of horizontal thrust and then determination of crack pattern. Therefore, the presented paper provide a new analysis tool for a computer procedure able to take into account the three- dimensional effects in the vaults and the vaults' safety factor.

\section{REFERENCES}

[1] O.C. Zienkiewicz, R.L. Taylor, "The Finite Element Method", London, 1993.

[2] H.J. Bathe, "Finite element procedures in engineering analysis", Prentice-Hall, Englewood Cliffs, New Jersey, USA, 1982.

[3] J. Heyman, "Arches, vaults and buttresses: masonry structures and their engineering", Varorium Ashgate Publishing, 1996.

[4] J. Szolomicki, "Statical-stentgth analysis and computational modeling of masonry constructions". Ph.D. Dissertation, Wrocław University of Technology, Wrocław, 1997.

[5] S.S. Ali, A.W. Page, "Finite element model for masonry subjected to concentrated loads", Journal of Structural Engineering ASCE, vol. 114, 1988.

[6] G. Milani, E. Milani, A. Tralli, "Upper bound limit analysis model for FRP-reinforced masonry curved", Computer and Structures, vol. 87 , pp. 1534-1558, 2009.

[7] T.A. Ozkul, E.Kuribayashi, " Structural characteristics of Hagia Sophia: I-A finite element formulation for static analysis", Building and Environment, vol. 42, 2007..

[8] T.A. Ozkul, E.Kuribayashi, "Structural characteristics of Hagia Sophia: II-A finite element formulation for dynamic analysis ", Building and Environment, vol. 42, 2007.

[9] A. Zucchini, P.B. Lourenço, "A micro-mechanical model for the homogenization of masonry", International Journal of Solids and Structures, vol. 39, pp. 3233-3255, 2002... 